\title{
Gaucheroma hepático. Un pseudotumor que puede confundir al radiólogo. Reporte de un caso
}

\section{Hepatic Gaucheroma. A Pseudotumor that can confuse the Radiologist. Report of a Case}

\author{
Mildred Valeria Pico Poveda ${ }^{1}$ Elizabeth Mina Romero ${ }^{1}$ \\ Israel Amores Grandes ${ }^{1}$ Vanessa Freire Balseca ${ }^{3}$ \\ ${ }^{1}$ Servicio de Radiología, Hospital José Carrasco Arteaga, Cuenca, \\ Ecuador \\ 2 Servicio de Radiología, Hospital de Especialidades Guayaquil Dr. Abel \\ Gilbert Pontón, Guayaquil, Ecuador \\ ${ }^{3}$ Servicio de Patología, Hospital San Francisco de Quito, Quito, \\ Ecuador
}

Rev Argent Radiol 2020;84:33-35.

\section{Estimados editores:}

La enfermedad de Gaucher (EG) pertenece a un grupo de enfermedades autosómicas recesivas causadas por la actividad deficiente de la B-glucocerebrosidasa, una enzima necesaria para el catabolismo intralisosomal del glucocerebrósido. Eso conduce a un acúmulo del mismo en los lisosomas de macrófagos de los tejidos del sistema reticuloendotelial. ${ }^{1}$

En la literatura existen pocos casos publicados sobre las características por imagen de esa entidad benigna. Nuestro objetivo es describir los hallazgos por tomografía computada (TC) de la lesión hepática focal que puede simular una hiperplasia nodular focal (HNF) o un carcinoma hepatocelular (HCC) con cicatriz central.

Se presenta el caso de un paciente masculino de 61 años, con antecedentes de EG tipo 3 sin terapia de reemplazo actual, esplenectomizado, con cuadro clínico compatible con cirrosis y múltiples fracturas patológicas a nivel de clavícula, húmero, radio, cúbito y algunos cuerpos vertebrales, con valores de beta-glucosidasa bajos, 67,15 (valor de referencia 200-2000) y marcadores tumorales negativos. La TC de abdomen evidenció múltiples lesiones nodulares distribuidas en forma difusa en el parénquima hepático ( Fig. 1); siendo la de mayores dimensiones de 5,3 $\times 4$, $2 \times 5,1 \mathrm{~cm}$, localizada en el lóbulo hepático izquierdo, segmento IV, de morfología redondeada, bordes parcialmente lobulados, tenuemente hiperdensa al parénquima hepático circundante, 80 Unidades Hounsfield
Address for correspondence Mildred Valeria Pico Poveda, Condominio El Jardín, Viracochabamba y Pachacama, Cuenca, Ecuador (e-mail: k.a.rusav@hotmail.com).

(UH) en fase simple, con zona central de menor atenuación 31 UH por probable degeneración quística-necrótica.

Tras la administración de contraste endovenoso, durante la fase arterial se observó un leve refuerzo de tipo heterogéneo, con realce de la región periférica $101 \mathrm{UH}$, manteniendo la zona central hipodensa. En la fase venosa portal, la lesión mantuvo el patrón de refuerzo con predominio hacia la periferia $104 \mathrm{UH}$. Durante la fase venosa tardía (tres minutos tras la inyección de contraste intravenoso), la lesión se mostró isodensa al parénquima hepático circundante. El área central permaneció sin cambios durante todo el estudio dinámico (-Fig. 2). Finalmente, la anatomía patológica, a partir de una muestra obtenida mediante biopsia percutánea guiada por TC, confirmó el diagnóstico de gaucheroma hepático (-Fig. 3).

La EG, descrita por Philippe Gaucher en 1882, representa en la actualidad la enfermedad por almacenamiento lisosomal más frecuente. ${ }^{1}$ Según datos del Registro de Gaucher del Grupo Colaborativo Internacional de Gaucher (ICGG, por su sigla en inglés), hasta el 1 de febrero del año 2013, fueron ingresados al registro 5.986 pacientes provenientes de 60 países diferentes. ${ }^{2}$

El proceso fisiopatológico que induce las manifestaciones clínicas en la EG ocurre por disminución de la actividad enzimática de la B-glucosidasa, lo que provoca un acúmulo de glucocerebrósidos en cantidades masivas dentro de los lisosomas de las células fagocíticas del sistema reticuloendotelial. Esas células distendidas se conocen como células de Gaucher. ${ }^{3}$
DOI https://doi.org/ 10.1055/s-0039-1693670. ISSN 1852-9992.
Copyright @ $\odot$ 2020, Sociedad Argentina de Radiología. Publicado por Thieme Revinter Publicações Ltda., Rio de Janeiro, Brazil. Todos los derechos reservados.

\section{License terms}

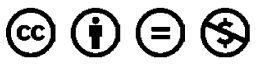



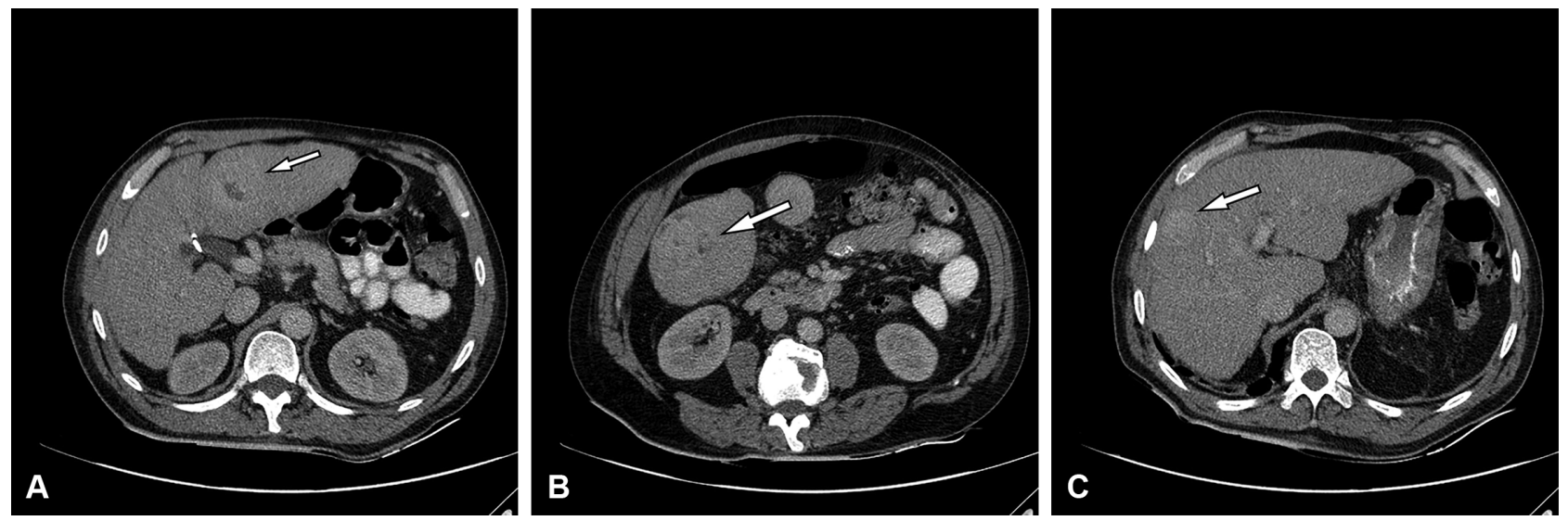

Fig. 1 Cortes axiales de TC, fase venosa portal donde se hacen más evidentes lesiones nodulares, de tamaños variables, distribuidas en forma difusa en el parénquima hepático, (A) segmento IV, (B) segmento VI, (C) segmento VIII.

Clínicamente, la enfermedad se ha dividido en tres tipos, conforme a la ausencia o presencia de síntomas neurológicos, siendo los órganos más afectados el bazo, el hígado y la médula ósea. ${ }^{4,5}$

El reemplazo de la médula ósea por células de Gaucher puede producir áreas de erosión, deformidades esqueléticas e incluso fracturas. ${ }^{1}$ A nivel cerebral, las células de Gaucher están en los espacios de Virchow Robin, representando de alguna forma un componente tóxico para el tejido neural. ${ }^{4}$

En el hígado se han reportado algunos patrones de infiltración de células de Gaucher, incluyendo el reemplazo total del parénquima hepático, así como focos agrupados de células de Gaucher, llamados gaucheromas. ${ }^{5}$

Según Patlas M. y col., en una serie con 103 pacientes pediátricos, la hepatomegalia es el hallazgo por ultrasonido más frecuente, con una prevalencia del $100 \%$, siendo el reemplazo extenso del parénquima hepático por células de Gaucher el proceso fisiopatológico atribuido al mismo. ${ }^{7}$

Según Regenboog M. y col., ${ }^{5}$ en una serie reportada en 2016 con 91 pacientes diagnosticados de EG, la afectación como lesión focal única o múltiple presenta una prevalencia del $25 \%$. Esas lesiones pueden simular otras patologías, tanto benignas como malignas, por lo que el gaucheroma debe incluirse en el diagnóstico diferencial.

Un rasgo en común del gaucheroma con la hiperplasia nodular focal y algunas variantes del hepatocarcinoma, que pudimos observar en el presente caso es la presencia de una cicatriz central hipodensa. Sin embargo, en la HNF, la cicatriz central suele realzar en fases tardías y, en el HCC, la cicatriz es mucho más prominente y presenta un mínimo realce en fase tardía, además de que típicamente la región periférica se presenta con realce heterogéneo en la fase arterial y pérdida rápida del refuerzo (washout) en la fase portal. No obstante, debido al riesgo incrementado en los pacientes con EG de desarrollar HCC, es importante detallar meticulosamente las características imagenológicas de esas lesiones y mantener un seguimiento, sobre todo en pacientes esplenectomizados. ${ }^{4}$

Por último, es preciso mencionar que, además de la hepatomegalia y lesiones focales únicas o múltiples, en los
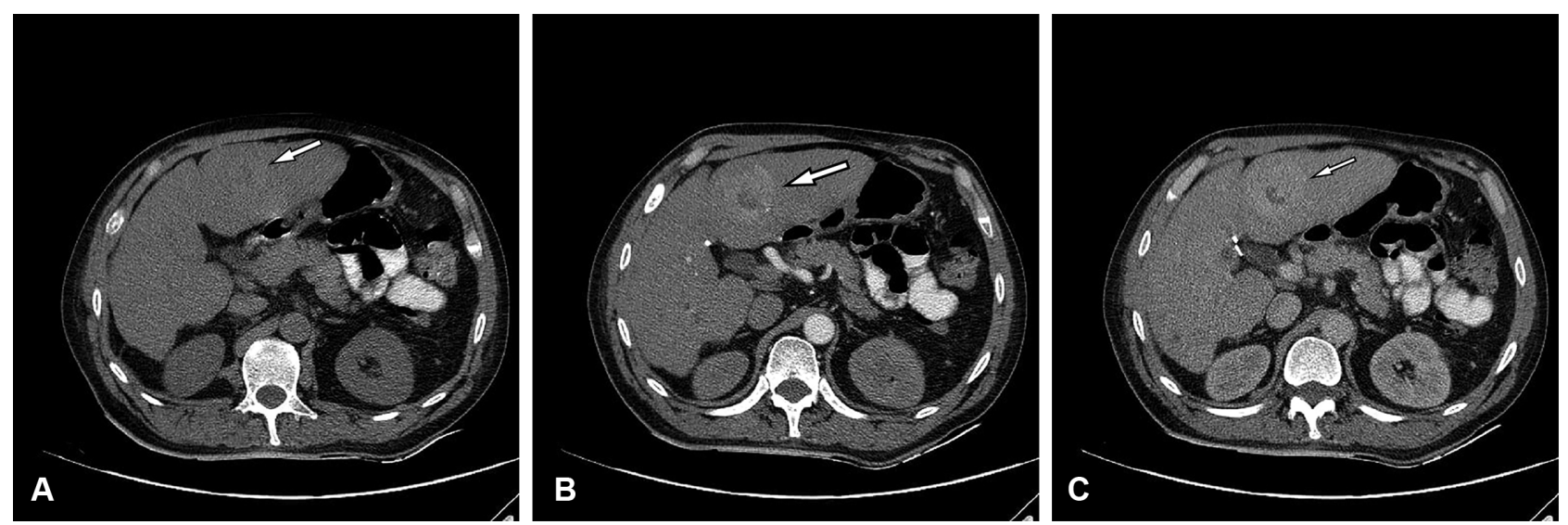

Fig. 2 Cortes axiales de TC, lesión localizada en el lóbulo hepático izquierdo, segmento IV. (A) Durante la fase simple existió dificultad para identificar la lesión, la misma que se mostró tenuemente hiperdensa con respecto al parénquima circundante; (B) en fase arterial la lesión presentó un refuerzo heterogéneo, con mayor realce de la zona periférica y área central hipodensa. (C) En la fase venosa portal la lesión mantuvo el patrón de refuerzo con predominio hacia la periferia. Durante la fase venosa tardía (no se muestra), la lesión se observó isodensa al parénquima adyacente, sin cambios en el área central, que permaneció de baja atenuación durante todo el estudio dinámico. 

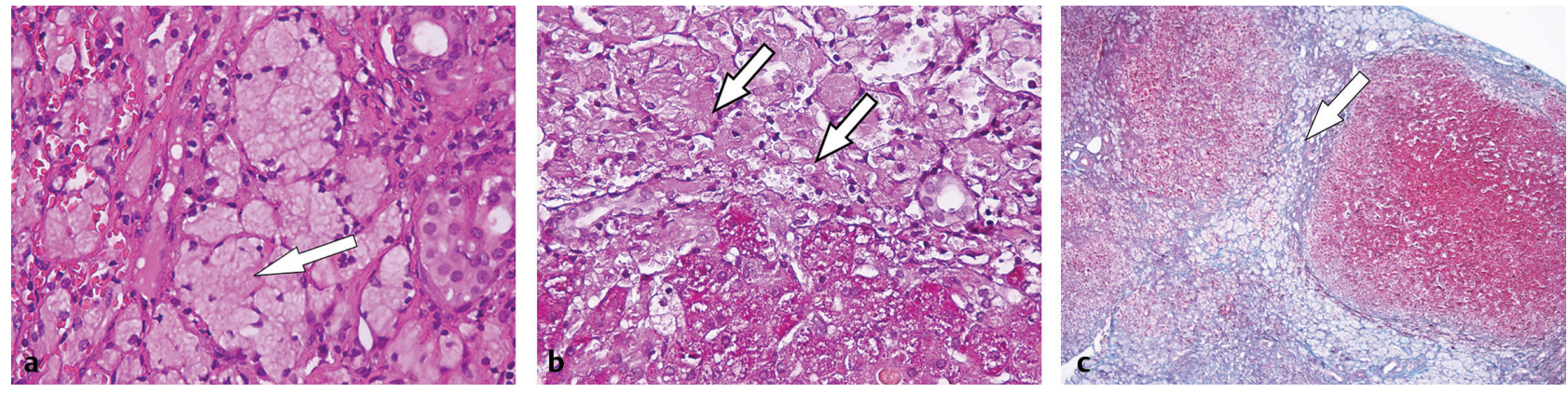

Fig. 3 Microfotografía de nódulo hepático (A) en un preparado de rutina teñido con hematoxilina eosina (original magnificación, 400 x), que muestra parénquima hepático con un extenso infiltrado de macrófagos marcadamente distendidos, con citoplasma estriado característico, que se disponen formando nidos y sábanas (B) tinción Periodic Acid-Schiff (original magnificación 400x) y (C) tinción tricrómica (original magnificación $200 \mathrm{x}$ ), que muestra tejido hepático circundante de aspecto fibroso y congestivo.

pacientes con EG, existen otras manifestaciones de compromiso hepático tales como colelitiasis, hepatitis autoinmune, hepatitis viral, esteatosis, hipertensión portal, fibrosis y cirrosis, hasta el potencial desarrollo de un hepatocarcinoma, condiciones que han sido relacionados a la terapia de reemplazo enzimático, al proceso inflamatorio y apoptótico así como a la sobrecarga de hierro. ${ }^{3}$

\section{Confidencialidad de los datos}

Los autores declaran que han seguido los protocolos de su centro de trabajo sobre la publicación de datos de pacientes, y que todos los pacientes incluidos en el estudio han recibido información suficiente y han dado su consentimiento informado por escrito para participar en dicho estudio.

Conflicto de intereses

Los autores del trabajo declaran no tener ningún conflicto de intereses.

\section{Bibliografia}

1 Simpson WL, Hermann G, Balwani M. Imaging of Gaucher disease. World J Radiol. 2014;6(09):657-668. Doi: 10.4329/wjr.v6.i9.657

2 Drelichman G, Basack N, Fernández Escobar N, Watman N, Bolesina M, Elena G, et al. Consenso para la Enfermedad de Gaucher. Hematología. 2013;17:25-60

3 Adar T, Ilan Y, Elstein D, Zimran A. Liver involvement in Gaucher disease - Review and clinical approach. Blood Cells Mol Dis. 2018; 68:66-73. Doi: 10.1016/j.bcmd.2016.10.001

4 Dandana A, Ben Khelifa S, Chahed H, Miled A, Ferchichi S. Gaucher Disease: Clinical, Biological and Therapeutic Aspects. Pathobiology. 2016;83(01):13-23. Doi: 10.1159/000440865

5 Regenboog M, Bohte AE, Somers I, van Delden OM, Maas M, Hollak CE. Imaging characteristics of focal splenic and hepatic lesions in type 1 Gaucher disease. Blood Cells Mol Dis. 2016;60:49-57. Doi: 10.1016/j.bcmd.2016.06.009

6 Patlas M, Hadas-Halpern I, Reinus C, Zimran A, Elstein D. Multiple hypoechoic hepatic lesions in a patient with Gaucher disease. J Ultrasound Med. 2002;21(09):1053-1055. Doi: 10.7863/jum.2002. 21.9.1053

7 Ayyala RS, Teot LA, Perez Rossello JM. Gaucher disease in the liver on hepatocyte specific contrast agent enhanced MR imaging. Pediatr Radiol. 2017;47(04):484-487. Doi: 10.1007/s00247-017-3779-z 